\title{
Global Observatory for eHealth (GOe) Survey in Sri Lanka
}

\author{
Dr. Rasika Rampatige MBBS, MSc, MD \\ Consultant Community Physician \\ Dr. M H Abusayeed BDS \\ Medical Officer \\ Dr. Himan Galappaththi MBBS \\ Medical Officer, \\ Planning Division, Ministry of Health, Suwasiripaya, Colombo 10, Sri Lanka \\ E-mail address: Dr. R. Ramaptige - rampatige@gmail.com
}

Sri Lanka Journal of Bio-Medical Informatics 2010;1(1):49-52

DOI: 10.4038/sljbmi.v1i1.1485

\begin{abstract}
The Global Observatory for eHealth (GOe), is an important initiative established in 2005 by the World Health Organization (WHO), designed to provide countries with strategic information and guidance on effective, practices, policies and standards in eHealth. The second eHealth survey was conducted in 2009 where Sri Lanka too participated. This short report is based on the findings of the GOe Survey for Sri Lanka. The second GOe survey had seven sections. The survey was completed with contributions from identified stakeholders of eHealth in Sri Lanka.

The foundation for e-Sri Lanka is led by Information and Communication Technology Agency (ICTA) of Sri Lanka. The country has favourable foundation and organization support to introduce eHealth activities. Many organizations and individuals has designed and implemented eHealth related activities but the efforts lack central coordination.
\end{abstract}

Keywords: GOe, eHealth, Survey

\section{Introduction}

eHealth is the use of information and communication technologies (ICT) for health. It is recognized as one of the most rapidly growing areas in health today. However, limited systematic research has been carried out to form eHealth policy and practice. The Global Observatory for eHealth (GOe), is an important initiative established in 2005 by the World Health Organization (WHO), designed to provide countries with strategic information and guidance on effective, practices, policies and standards in eHealth ${ }^{(1)}$. GOe initiative provides timely and high-quality evidence and information to help national governments and international bodies to improve policy, practice, and management of eHealth services. The first GOe survey was conducted in 2005 and the second survey was conducted in 2009. This short report is based on the findings of the second survey for Sri Lanka. The second GOe survey had seven sections. The survey was filled with contribution of identified stakeholders of eHealth in Sri Lanka.

\section{Findings}

\section{eHealth Foundations for Actions}

One of the sections the survey looked at was the eHealth foundations for actions in Sri Lanka. The Information and Communication Technology Agency of Sri Lanka (ICTA) was established in July 2003 and under the Information and Communication Technology Act No. 27 of 2003, (ICT Act). ICTA became the apex ICT institution of the Government, presently 
functioning within the purview of the Presidential Secretariat. Under the ICT Act No. 27 of 2003 ICTA was empowered to formulate and implement strategies and programmes in both the Government and the private sector and pursuant thereto ICTA prepared programs and strategies on Information and Communication Technology, which are presently embodied in the "e-Sri Lanka Development Project" (2). At the moment there is no national eHeath policy in Sri Lanka and the country is expected to formulate an eHealth policy by 2012. The policies for procurements related to ICT are incorporated in the ICT act ${ }^{(3)}$. In Sri Lanka funding for eHealth usually come from government or donor agencies. The World Bank and the World Health Organization has been identified as the two main leading organizations that fund the eHealth related activities in the country.

\section{mHealth (Mobile Health)}

mHealth is an emerging term for medical and public health practice supported by mobile devices such as mobile phones, patient monitoring devices, Personal Digital Assistants (PDAs), and other wireless devices. mHealth applications include the use of mobile devices in collecting community and clinical health data, delivery of healthcare information to practitioners, researchers, and patients, real-time monitoring of patients' vital signs, and direct provision of care.

The Ministry of Health has not adopted mHealth as a policy. However, there are many mHealth activities in the country all of which operate to cater to the needs of the organizations. Sarvodhay, one of the NGOs uses real-time Bio-Surveillance System for data transfer and messaging system through mobile technology. It is a web based collaboration tool that not only supports the disease surveillance system but also it addresses common coordination problems during a disaster from finding missing people, managing aid, managing volunteers, tracking camps effectively between Government groups, the civil society (NGOs) and the victims themselves. In addition, the system has the capability to transfer the message through mobile technology and integrate and make reports for decision making ${ }^{(4)}$.

Poison information centre located in the National Hospital of Sri Lanka provides information to anybody who needs information regarding any poisoning incidence and emergency management through toll free hotline. Voice communication technology is mainly used for the purpose ${ }^{(5)}$. Voice telephony is used to coordinate the activities to provide the health care services for the internally displaced population in the Northern part of Sri Lanka. Mobile voice communication CDMA phones are used for sectoral and intersectoral coordination for effective and efficient health service delivery ${ }^{(6)}$.

Since there is no comprehensive study evaluating the cost effectiveness of the mHealth initiative the cost effectiveness of mHealth initiatives not known. The lack of national policy of use of mHealth, demand, knowledge on usefulness and applications of eHealth are identified as barriers to implement mHealth initiatives in Sri Lanka.

\section{Telemedicine}

Telemedicine (also known as telehealth) falls under the broader term of eHealth and involves the delivery of health care services, where distance is a critical factor. The telemedicine approach uses information and communication technologies for the exchange of information for diagnosis, treatment and prevention of diseases, for research and evaluation, and for the continuing education of healthcare providers. Sri Lanka does not have a national agency committed for the development and promotion of telemedicine and its applications. However, 
there are few organizations namely the WHO, Ministry of Health, University of Colombo had launched telemedicine initiatives. The Vidusuwa telemedicine initiatives lead by ICTA is the so far most successful telemedicine institute in the country (7). The Human Genetics Unit of University of Colombo has established a tele-consultation project through "Nanasala" (8). Possible barriers to telemedicine projects include lack of policy and legal framework on telemedicine, knowledge on applications and usefulness.

\section{eLearning in Health Sciences}

eLearning refers to the use of ICT for learning. It can be used to improve the quality of education, to increase accessibility for geographically isolated persons or those who have poor local learning facilities, and to make new and innovative forms of education potentially available to all. It is increasingly used for training health sciences students and for the ongoing development of health professionals. Although not widely established yet, eLearning has begun to take importance in teaching health sciences in the country. The Postgraduate Institute of Medicine has introduced web based post graduate courses in toxicology and some professional colleges now beginning to use eLearning as a tool to promote continuing professional development for their members. Lack of policy, commitment, knowledge on usefulness and applications of eLearning, and short comings in supportive infrastructure has been identified as possible barriers to eLearning.

\section{Management of Patient Information}

Access to patient information plays a vital role in the provision of effective clinical care by health professionals. Diagnosis and treatment can be improved if health professionals have easy access to accurate and comprehensive medical records of patients.

Electronic Medical Records / Electronic Health Records (EMR/EHR) are often referred to interchangeably and will be interchangeable for the purpose of this survey. An EMR/EHR is a real-time longitudinal electronic record of an individual patient's health information that can assist health professionals with decision-making and treatment. Data found in a record may include patient demographics, past medical history, vital signs, examination and progress notes, medications, allergies, immunizations, laboratory test results, radiology reports, living wills, and a health power of attorney. It can be made rapidly available through ICT to authorized personnel providing patient care in different locations including across national boundaries. It can also support the collection of data for other uses such as billing, quality management, public health disease surveillance and reporting. Extent of usage is not widespread in the country. Most of the hospitals in the country use manual health records. There are a few ongoing projects in the country to introduce electronic patient records. These projects are implemented in a phase-wise manner especially in the North Central, Eastern and North Western Provinces.

\section{Legal and Ethical Frameworks for eHealth}

An increasingly connected world poses enormous possibilities in the way we work and live, and in the nature and quality of services we receive. With these opportunities the serious challenges that will need to be addressed if personal and health-related data are to remain secure.

The privacy and security of personal and health-related data of all individuals is protected in most countries by specific data protection legislation. Legislation generally applies to data irrespective of whether it is held on paper or in electronic format. This section of the survey explores the development of specific legislation to cover the storage and transfer of an 
individual's medical/ health information contained in Electronic Medical Records / Electronic Health Records (EMR/EHR) which have been created and managed by a health care entity. (The questions do not apply to Personal Health Records which are created by companies or individuals and held on a web site or on their own personal computer.)

The manual patient records in Sri Lanka is considered as a legal document and it is supposed that only the authorized people can have access to the patient records. Sri Lanka has not formulated any legislation to ensure privacy of personally identifiable health data in digital format. However, some applications that are used currently have some inbuilt features that facilitate the confidentiality of the patient information.

\section{Organization and Support for eHealth}

The Global Observatory for eHealth is developing a database of key organizations and professionals to facilitate international communication, networking and sharing of knowledge in eHealth. The Health Information centre of the Ministry of Health, ICTA Sri Lanka and the University of Colombo, School of Computing can be identified as the main institution that provide organizational support for eHealth initiatives of the country while the main association that provide leadership in eHealth is the Health Informatics Society of Sri Lanka (HISSL).

\section{Conclusions}

In summary, Sri Lanka has favourable foundation and organization support to introduce eHealth activities. Many organizations and individuals have designed and implemented eHealth related activities but the efforts lack central coordination.

\section{References}

1. Global Observatory for eHealth (GOe), Available from http://www.who.int/kms/initiatives/ehealth/en/ Accessed on 19 September 2009.

2. Information and Communication Technology Agency of Sri Lanka, e-Laws Project, Legislation having an impact on ICT development in Sri Lanka, Available from http://www.icta.lk/index.php/en/e-laws-project\#LEG Accessed on 19 December 2009.

3. Personnel Communication with Ministry of Health Official, August 2009.

4. Personnel Communication with a Project Manager, Sarvodhaya, August 2009.

5. Personnel Communication with Medical Officer, Poison Centre, National Hospital Sri Lanka, August 2009.

6. Personnel Communication with Coordinator, Disaster Preparedness and Response Unit, Ministry of Health, August 2009.

7. Vidu Suwa eHealth Initiative, Available from http://www.vidusuwa.com/ Accessed on 20 September 2009.

8. Human Genetics Unit, Faculty of Medicine, University of Colombo, Available from http://www.hgucolombo.org Accessed on 20 September 2009. 